To cite: Arora, P. (2012). Your kool-aid is not my kool-aid: Ideologies on Microfinance within an INGO Culture, Development in Practice, 22(7), 1006-1018.

\title{
TITLE
}

'Your kool-aid is not my kool-aid': Ideologies on Microfinance within an INGO Culture

\section{Payal Arora, PhD}

\author{
Department of Media and Communication \\ Faculty of History, Culture and Communicatoin \\ Erasmus University Rotterdam
}

Development investigations focus on synergies of institutional cultures for policy and practice. International Non-Government Organizations (INGOs) currently enjoy a privileged position as harbingers of world culture unity. While there is contestation on INGOs as monolithic entities, few studies delve into the voices of actors within INGOs to provide for a more pluralistic perspective. This paper separates the actors from their institution by examining their different socio-cultural takes that drive them. This emphasizes that as projects and visions come and go, institutional actors draw on their own philosophy that does not necessarily mirror their institution's stance. Here, we focus on one of the most important current development initiatives of our time - microfinance, revealing individual understandings on what is sustainability, role of external actors, indicators of success, exit strategies, and ethical action. In spite of situating this in the microfinance area, what is revealed is that actors are motivated by their own constructed ideology, often alluding peripherally to the specifics of microfinance. This opens another avenue of enquiry as to why organizational ideologies and popular development visions such as microfinance take on such diversity of forms and outcomes. Contrary to the world culture unity model, such communication disjunctures can be useful in understanding diverse development outcomes.

Key words: INGOs, microfinance, development policy, organization culture, intercultural discourse, decision-making, ideology

\section{Introduction}

There have been numerous studies as part of the recent globalization scholarship that celebrate the convergence of institutional cultures towards a "single world polity" (Boli \& Lechner, 2005). This euphoria of a "world culture" has spawned shared cultural frameworks amongst different institutional actors, a reversion to the archaic notion of the zero-sum game 
wherein all actors can enjoy a win-win solution. Building on years of critique from across disciplines on the unilateral policies and performances of State and International Global Organizational (IGO) actors such as the World Bank, United Nations, International Monetary Fund, and World Trade Organization, there has been a concerted effort to find common ground across stakeholders. In particular, International Non-Government Organizations (INGOs) have been looked at as harbingers of a new age of world culture (Jones, 2002).

However, the topic of "culture" has always and continues to be contested by scholars especially of an anthropological bent. Through the capturing of ethnographies of resistances and transformations, scholars problematize the romantic notions of INGOs as disinterested, monolithic homogenous entities with a shared vision and purpose (Anderson-Levitt, 2003). Through the juxtaposing of development rhetoric with ground level practice, these scholars have been successful at shedding light on the multiplicity of roles INGOs occupy and their plethora of interests, often competing with other INGOs in the process of shaping and fulfilling common goals. As the organization's "mission" enacts, interacts and gets interpreted by their beneficiaries at the ground level, it reveals diverse ways in which policies, stemming from the INGOs get creolized by local actors as a strategic means to deal with such interventions.

While the unpacking of these singularities has revealed a range of institutional cultures amongst INGOs defying easy categorization (as well as the ingenuity of the "beneficiaries" themselves in this process), few studies delve into the plurality within the organization culture. In fact, few development studies focus on understanding the internal dynamics within INGOs as they find themselves unwittingly at the forefront of the development parade (crusade if you will), for global unity. Thereby, this paper separates the actors from their institution by examining their different socio-cultural takes on microfinance. Here, it argues that as projects and visions come 
and go, institutional actors build their own philosophy that does not necessarily mirror their institutional or even team members stance on issues encountered. This is important to keep in consideration as we struggle to understand why even the most popular development projects of the time (in this instance microfinance, with its well-laid out vision and best practices manifesto) get played out in a plethora of ways. Decisions, thereby, are not a simple outcome of an organization's mission, but are a product of an accumulated wealth of past practices, encounters and personal histories. Here, we capitalize on other disciplines by drawing from scholarship on organizations and intercultural communication to better understand the implications of such practices.

This paper starts by laying the foundation of the popular understandings of microfinance and its current practices, debates and controversies, followed by scholarship on how decisions are made from within organizations. This work is situated in the case study of ImpactUS, an INGO, and its embarkation on the self-help group strategy in response to the Microfinance debates. Given that the author worked with this organization for an extended period of time, conversations with its key actors is shared through a set of mediated questions that intend to reveal important dimensions of microfinance -sustainability, exit strategies, role of donors, to overarching ethical concerns. This brings to light the splintered discourses, often away from the main topic of microfinance, revealing how decisions are driven from an implicit and larger development philosophy that has been tailor-made through years of acting on the development stage.

\section{Who doesn't love Microfinance?}


Over the last two decades, microfinance has become the darling child of development, providing a new means to poverty alleviation through partnership with the poor (Author, 2006). The year 2005 was proclaimed as the International Year of Microcredit by the General Assembly of the United Nations, giving impetus to microcredit programs throughout the world. The concept of microfinance was pioneered around 1976 in Bangladesh by Dr. Muhammad Yunus ${ }^{1}$, the winner of the 2006 Nobel Peace prize, who sought to make financial provisions to clients conventionally excluded from the financial system on account of their lower economic status. Perhaps most distinct from traditional banking is its "joint liability" feature, which views a group of individuals as a single client to whom the credit is disbursed.

Over these years, the idea of microfinance has taken on multiple forms, generating a new crop of enthusiasts and sufficient success stories to convert this development idea into a sacred mission for poverty eradication. As with any idea released into the wild, there has been a range of approaches to materializing it. Perhaps one of the most popular manifestations of this idea is the social business model approach wherein it attracts the private banking sector into the development arena by promising that they can do good as well as make a profit - the ultimate win-win game. This is founded on the key tenet that

....poor households demand access to credit, not cheap credit. Thus, programs can charge high interest rates without compromising outreach. If the argument is right, much poverty alleviation can be achieved at no cost to governments and donors - or perhaps even at a small profit. The vision has been translated into a series of "best practices" circulated widely..." (Morduch, 2000, p. 617).

In fact, Private Public Partnerships (PPP) has served as the main kool-aid within development practice for well over the last decade (Author, 2005). One can view the microfinance project as an outcome of a number of popular ideas finally finding a common ground and purpose - the 
empowerment discourse, the bottom of the pyramid (BOP) concept and the participation mantra, all woven in to feed into its vision.

However, recent events such as the microfinance crisis in Andhra Pradesh have brought this idea to its knees, compelling practitioners to ask if this is the end of the commercial approach to banking for the poor:

Tragically, this was a 'boom-to-bust' crisis foretold. Along with the Bolivian microfinance crisis of 1999-2000, the precursor (mini-crisis) to today's full-blown crisis that took place in AP itself in 2006, the series of boom-to-busts that have occurred in Bosnia, Pakistan, Morocco, Nicaragua and elsewhere in recent years, and let's not forget too the granddaddy of them all - the sub-prime-led financial sector meltdown in the USA from 2007 onwards -, there were in fact a whole street full of red lights flashing to warn policy-makers to avert the massive over-expansion of microfinance in AP. (Bateman, 2010)

While these conversations currently unfold, it has given life to some insightful critiques on microfinance practice, particularly highlighting the urgency to address the "schism" between institutionists, with their emphasis on financial self-sufficiency and scale, and the welfarists, those that emphasize direct poverty alleviation among the very poor (Woller, Dunford, \& Warner, 1999, p.29). This thinking finds its roots in the classic scholarship by Murdoch, bringing our attention to the proposal that the win-win proposition rested on a series of myths:

First, that raising the costs of financial services does not diminish demand. Second, that due to their scale, financially sustainable programs can make the greatest dent in poverty. Third, that financial sustainability will give programs access to commercial financial markets. Fourth, that since they come at no cost to donors, financially sustainable programs are superior weapons for fighting poverty. Fifth, that subsidized programs are inefficient and thus bound to fail. Sixth, that subsidized credit most often ends up in the hands of the non-poor. Seventh, that successful microfinance programs must be nongovernment programs. And, eighth, that subsidizing credit undermines savings mobilization (2000, p. 620).

This revival of serious critique within this realm is a big step given that for the last few decades, microfinance has been placed on a pedestal in development practice: 
Microcredit has remained somewhat insulated from critical scholarly inquiry and the few existing critical analyses have not been politically popular within academic and policy circles...harsh critics of claims about microcredit are silenced by labeling them as being idealistic, impatient for results, and as lacking concern for the immediate needs of the poor. (Fernando, 2006, p.4)

This has also inspired INGOs to look at alternative ways to approach microfinance in a concerted effort to not throw the baby with the bathwater. This paper focuses on one such case study wherein self-help-groups have been chosen as a main strategy to operationalize microfinance. The rationale is that while microfinance as an institution continues to serve as a legitimate and alternative banking system for the marginalized, it is still confined by its conventional institutional structure that limits its capacity to serve the poorest of the poor (Author, 2006). This has increased attention to the more informal networks of self-help groups, a novel community finance savings and lending method that seeks to validate and leverage local social capital for sustainable growth. The self-help method is an informal means of building social capital within disadvantaged communities to foster savings and lending among these groups for autonomy from formal credit systems. This shift from a credit to savings-led approach adopted by Impact is an alternative take within microfinance sectors in development agencies.

Interestingly, while there has been substantive literature on microfinance given its persistent stardom over the decades, much has focused on its impact on empowering women, quantifying its financial impact on communities, it's outreach and scalability, and its linkages with the formal banking sector (Ringmar, 2005). Overall, disproportionate attention has been given to measuring outcomes and less on the actual processes and strategies involved in implementation, implying a generally unproblematic decision-making approach to microfinance.

To sum up, this section builds context of the past to ongoing dynamics of microfinance within which the INGO ImpactUS is operating and making decisions. While these discussions on 
microfinance and its current upheavals are indeed worthy of pursuit, the scope of this paper is to highlight how actors within an INGO institution work through such development transitions by creating a more general and stable ideology to reference for their actions. Here, we pay attention to key decision makers within this INGO to see how their constructs collude and collide and their linkage to the microfinance project. While no doubt this is sparse data, the goal here is to illuminate the nuances in discourses on this subject, argued to be (for the most part) unexamined in current development literature.

\section{Intercultural Discourses and Decision-Making within Organizations}

To understand INGOs in the context of their individual staff actors shaping development, we need to step outside of development studies and draw from scholarship on organization culture and intercultural communication. Within these fields, we see two divergent strands in the understanding of organization culture: the first is the investigation of symbolic aspects within organizations that allows for an interpretive approach through countercultures; the second and more dominant strand is the identifying of patterns amongst groups to allow for adaptability amongst actors with their environment at large (Rosaldo, 1989). Much investigation has gone into subcultures, leaning towards integrationist views where the main purpose is to locate overriding themes that foster organization consensus.

In recent years, there has been a growing interest in viewing organizational culture as fragmentations of subcultures where internal conflicts are viewed as potentially positive for organizational growth and dynamism (Cummings \& Worley, 2005). Less emphasis is placed on convergence of communicative practices and more on leveraging of divergence to propel innovative decision-making. Also, much investigation has gone into the actors and the actions 
and less on the process through which the act takes place; "ambiguity, complexity, and lack of coherence are the touchstones of the fragmentation perspective... their focus is on the understanders and the understood, not the understandings" (Batteau, 2001, p. 732).

Such dynamics of difference and similarity, of simultaneous resistance and adaptation is much of what constitutes organizational culture. Rather than being perceived as counterproductive to organizational culture, this kind of negotiation fosters and legitimates an atmosphere of inclusiveness, moving away from the illusive coherence of organizational systems to that which is a dynamic interplay of contending voices. While organizations offer "loose regimes of local diversity" in terms of spaces for contestation and appropriation, there continue to be boundaries of "functional differentiations" wherein roles are clarified, identities carved, standards met, and ideas ordered to reflect the culture of the organization (Batteau, 2001, p.728). This is important to keep in mind as we unravel the projected culture of the INGO ImpactUS and their stated mission, contrasted with the voices of some of its key actors on the microfinance project. As we see, individual ideologies flesh out in ways that do not easily and seamlessly cooperate with one another and may not always synchronize with the larger organization's mission. This should be viewed as a possible opening for innovation in new approaches to microfinance and not necessarily a serious flaw in INGO culture.

Furthermore, in relation to decision-making, there is a thin line between conflict and creativity. The navigation of such lines is contingent on the positioning of decision-makers within the organization (Bodea \& Mustata, 2007). Cultural identity interacts with organizational identity where the personal coordinates remain stable. This is often due to the status of the individual in the organization. When actors are in the position of making decisions, it compels a certain personal-driven behavior, shifting the organizational coordinates to suit them 
accordingly. We will see this occur time and again in the discussion section and how popular rhetoric of microfinance and development gets woven in with individual ideologies to gain legitimacy. This is important as popular understandings give us the impression that many development actors have bought into the microfinance kool-aid ${ }^{2}$, stifling innovation in this arena.

In fact, multiple decision-makers can keep this process "honest," where personal motivation, ideology, organizational interest, attraction of new clients, possibility of new markets and the like are factored in. This "professional evolution" (p.5) allows for a culture of decisionmaking that accommodates and even encourages conflict, especially at the nascent stage.

The goal in the end is to instigate all decision-makers to feel like genuine "ambassadors" of the organization. The bottom line here for these leaders is that "if they do not become conscious of the cultures in which they are embedded, those cultures will manage them" (Schein, 2004, p.375). In the context of the development world, this is essential to keep in mind as projects come and go and new visions replace sometimes the most sacred of beliefs. Microfinance is an excellent example given its current upheaval and its long established sacrosanct status (Roy, 2010). This, as we will see in the forthcoming section, compels the development veteran and "expert" to construct an ideology that is respectably detached from the organizations mission as well as the dominant euphoria that appears to have engulfed a professional world such as that of microfinance.

\section{The Missionary and its Mission}

Impact $U S^{3}$, a human-rights based INGO, hopes to lead by way of actively advocating a savings-led microfinance approach for eradicating poverty as part of their embrace of ideas on autonomy, community participation and grassroots capacity building. I worked with ImpactUS 
on a six-month project, identifying strategies in community microfinance. The ImpactUS team was meant to come up with support for the savings-led approach through self-help groups (SHGs) for poverty reduction in the most disadvantaged sectors in developing countries.

Impact in the United States is at a nascent stage in formulating and implementing savings-led community finance strategies for poverty reduction versus its branch in Europe, which has been in this field for about 30 years now. Yet, ImpactUS has chosen an execution model that is distinctly different from its sister firm. The prime difference between the two is that while ImpactEU works directly with their beneficiaries in implementation of their projects, ImpactUS works through NGO intermediaries in developing countries to reach their beneficiaries. This isn't sufficient reason to not share field experiences between the more experienced ImpactEU and its US partner to build institutional memory of failures and successes in this new savings method. Yet, through months of research at the US branch, it became apparent that there was a lack of inter-organizational communication within Impact as a whole with regard to sharing their experiences and knowledge on community finance projects. There was active discouragement to resemble the sister firm.

Additionally, even though the team was hired to document community finance to inform and shape microfinance strategy of ImpactUS, there was already a definite bias towards a savings-led approach through partnering with NGOs. It seemed that the prime interest in using this research was to validate their strategy rather than shape and inform it. This is based on the fact that the management team had fostered parallel efforts to create savings-led advocacy material for an upcoming launch independent of this research project. Also, they had already initiated dialogue with other INGO organizations for partnership in the savings-led approach in Africa, the first pilot project of ImpactUS in community finance. This seems to be a typical 
problem amongst INGOs in development where often the solution is the problem (Pritchett \& Woolcock, 2003). This is in reference to the politics of policy-making within INGOs when the problem sometimes can be the very structural design of the institution, requiring it to pioneer solutions in their own space, even if that involves reinventing the wheel. This often results in the outcome getting lost in the web of politics.

\section{Talking the Talk: Conversations, Recollections, Personalizations and...Pauses}

To gain an understanding of the culture and decision-making process of ImpactUS, I had discussions with three key staff members separately ${ }^{4}$ in the community finance department on issues in this development arena (see Chart 1). I was familiar with all three interviewees and had established a cordial relationship with each of them over these last few months.

I started out by asking the informants to define development based on their extensive field experiences and what drew them initially to this field. The first informant Thomas, an Iranian-American in his late 30s, defined development as the ability to gauge the interests of members of the world community to help them realize their rights and opportunities. He used "we" as in "we at ImpactUS" in describing development. As to what drew him to this field, he mentioned his field experiences in Bangladesh in a microfinance project that got him "hooked for life." The second informant Fatima, perhaps in her mid 40s, described development as "leveling the playing field" where access to resources is tied directly to the ability of people to speak for their own development. She further spoke about the sense of injustice in development. She personalized this by speaking of her own experiences in Burkina Faso where she was born and brought up:

I am from a privileged perspective yet from a context that is not privileged. What did I do to earn this? Based on ethnicity, depending on where I go, I can become the 
underprivileged. Now that's what development should aim to address and not just access to economic resources.

As for Todd who was well in his late 50s and the most senior amongst them all, he paused for a while before answering this question; “it's all about change isn't it? At ImpactUS we hope it's for the better." He then went into the history of ImpactUS's commitment to eradicating poverty in the world and until that was achieved, the need for development would live on. He had been in the field for the last 35 years and was considered an expert in self-help groups in certain circles in microfinance.

When it came to the topic of sustainability in microfinance, a fervent issue, Thomas suggested two approaches to address this. The short-term approach he said was purely the operating costs that either justified or did not justify the "intervention;" the long-term approach was the partnering with local NGOs in implementation of these projects; "the only way to enable sustainability is through the strengthening of local actors and community contacts which ImpactUS has been very good at." Fatima however said that this notion of sustainability is a fallacy as there will always be a violation of human rights; "we can't shut shop just because we think people have found their voice in the public sphere... for what is found can also be lost again." She went on to point out that development is a perennial effort and development NGOs need to be watchdogs in preserving these rights. As for Todd, his response to this topic was through a narrative of his experiences in Senegal where "after scratching the surface", his team was able to "dig out a number of local NGOs" already practicing the savings-led method for a good number of years. He spoke about strengthening the already existing local groups rather than trying to impose their ideas on the villagers as a means to sustainability. 
This line of questioning led to speaking about the role of external actors such as ImpactUS. Thomas stated that given that ImpactUS is a "neutral development body with no political affiliations", there is always a limitation to what it can achieve in a particular country. He gave the example of his experiences in Zimbabwe where his team had to work closely with the government who in turn favored communities who had voted for them while ImpactUS felt powerless to control this phenomenon; "we try to separate the two - political and ideological but that sometimes gets hard to do." He believed that in spite of this, it was important to stay clear from these political situations for ImpactUS to be most effective. Fatima on the other hand fervently expressed the view that ImpactUS as an INGO with its mission focus on human rights, is inherently deeply political. She spoke about funding as only part of the story, as being an international actor in itself gives an upper hand in bringing ideas from the outside;

We are political and are becoming more so. Poverty is not a coincidence where we just wake up and see that we are poor. It has to come from somewhere. We really have to start holding actors responsible and to stay neutral, we can worsen the situation. ImpactUS has no other choice but to be political... if we are just trying to save lives like the Red Cross then perhaps we can be neutral but not if we want long-term change. Just by funding partners, it makes us not neutral as our partners are not neutral themselves. In terms of being able to identify failures in human rights, we have to make a political decision to intervene. It's a risk but given the potential impact, it's a risk we're willing to take.

Todd in response to this issue took out a piece of paper and started to draw a chart which showed five circles and three out of five circles had arrows, each of the three leading towards five other circles which in turn grew exponentially into more circles with a loop coming back to the original circle. He indicated that this is how he envisioned how self-help-groups would work where Impact US was mere fodder for a burgeoning growth that was waiting to happen.

"But how were they to know what was working and what was not? And more importantly, when does one know when its time to leave?" I asked. In discussing indicators for 
$\underline{\text { success }}$ of a particular project and various exit strategies, Thomas spoke about the presence of women in leadership positions as a key sign of success in community finance. He again spoke about Zimbabwe where in this particular village that he visited over intermittent periods of time, the practice of self-help groups had permeated into other industries within the village over a period of two years. That to him was a real story of success. Fatima however saw this differently; her view was that exit strategies were often not associated by success stories and that there was a common pattern of unthinkingly linking the two phenomena as part of the same process; "these things take time and we don't have time. When the budget runs out, we've got to get out of the region regardless of the results produced." Todd spoke about the proud people of Africa and their generosity of spirit as a people with a rich heritage in attempting to address this issue; "when you see them walk proudly in the markets, you realize that these people are strong and resilient and have this amazing gift of smiling in the face of deep poverty."

I wrapped this discussion by asking the three of them of their biggest ethical challenges they had faced in implementing their projects. Thomas spoke about the dilemma of working in areas where the drive may often be that of self-interest; "I always ask myself why we have chosen a particular area and if we are helping the maximum number people but I have sometimes felt that I cannot answer the question." Fatima responded to this question by speaking of herself and her attitudes when she was interacting with other partners and beneficiaries:

When I am sitting in front of you, do I feel that you are truly equal to me? Who do I give the seat at the table to when I make decisions? These are struggles I think we constantly have to answer to.

Todd on the other hand remarked on the rights a people or civilization has to not change; "what if people want to be the way they are? Why should we institutionalize them and get them to pay taxes and make them like us? I don't know...you tell me." He spoke about the challenge of 
inaction as equal to that of action in development and at times it was hard to tell when to draw the line; "that's why I am not a real proponent of linking these self-help groups to formal banks. Why should they have debts and fall into that vicious cycle? No, not something I really think is necessary for everyone."

\section{Do we (need to) have consensus at the table?}

Strategies of implementation, as we see, have a rationale that ropes in personal experience and values with organizational values. There is no best practice. Rationales win, and not just outcomes. Intercultural dialogue here reveals the nuances in thinking that drives organizational behavior. To put the following in perspective and see the relationships between ImpactUS ideology and the informants' opinions, it is important to keep the mission statement in mind. All three interviewees took the human rights angle to most of the questions, aligning themselves with the ImpactUS mission statement. Yet the referencing to the larger discourse on human rights was used strategically to legitimate ones stance, as in Fatima's case, often contradicting certain sacrosanct concepts as in the issue of sustainability. Further, personalization was used to legitimate her stance with that from outside the organization. While embodying ImpactUS's ideology on human rights at an overt level, she particularized her judgments through personal articulations and affiliations with her past and current experiences.

With the question of partnerships with NGOs (versus directly servicing beneficiaries as in the case of its sister organization ImpactEU), there was already a normative belief in the partnering with NGOs as the best strategy for long-term efficacy. For example, Thomas espoused that for sustainability to be gained, going through the NGOs was "the only way" development could achieve long-term efficacy. Todd also held a similar viewpoint and made it 
clear by sharing his experiences in Senegal and talking about the grassroots NGO movements that were alive and thriving. While both ImpactUS and ImpactEU share a sisterhood of human rights, the boundary is clearly drawn, demarcating the US branch as that which believes in NGO partnerships, permeating the views of its actors. It is interesting to see what can and does get negotiated to what becomes part of the organization's normative fabric, highlighting the sacrosanct aspects of this organizational culture.

This issue gains further attention through the discussion on the role of the external actor, stimulating contradictory responses, particularly on lines of neutrality. While Thomas looked upon ImpactUS as a "neutral actor" even though he did acknowledge that it was a struggle, Fatima viewed the organization as a highly political one. What is interesting here is that the question itself did not have any reference to the political aspects of ImpactUS yet the respondents chose to interpret it through this lens. Ironically, the virtue of INGOs is embedded in its supposed neutral and apolitical nature, thereby perceived often as alternatives to States (Boli \& Thomas, 1999). Yet as we see, even within the organization itself, there is a politics of semantics where prevalent themes are strategically navigated, driven perhaps by personal agencies, historical and transnational relations, and social assemblages of day-to-day occurrences and emotive resonances at play.

Another policy challenge for ImpactUS was to determine its exit strategy and to know when the society being served was "ready" to be autonomous. This question however gained mainly vague responses that seemed to barely address the issue, from focus on budget issues to that of women's participation and African culture. Yet in terms of how much of women's participation was "enough" to exit the scene, there was an unmet silence. Sometimes these 
silences can be no less revealing of meaning than assertions, implying the implicit tensions underlying certain subjects.

As to the ethical challenge, Todd's response was the most unexpected in terms of policy as he directly referred to linkages to banking as not necessarily a positive effect in microfinance. This is important to keep in mind as he is the most influential player in this department. The rationale given here is based on the understanding that microfinance is an initiative that introduces the practice of banking to marginalized communities and if linkages are quickly made between the poor and banks, there is a good chance that the poor can get exploited. Basically, being relatively new to this process, the poor can get caught up in taking more loans than they can manage and become easy targets for banks that seek to capitalize on these new entrants. In a sense, Todd questions the common assumption that this is the only desirable outcome to microfinance and that it has to culminate in linkages with the private banking sector. He brings to question the responsibility of INGOs in mediating this process and providing alternatives for the poor in terms of informal banking systems such as local and informal cooperatives that may have more palatable interest rates for the poor. This stands against popular practice, where it is now generally agreed that it is important to have formal banking links to provide for vertical mobility (Rankin, 2004). However, the choice of savings-led as a step above the credit-led method according to ImpactUS policy guidelines is that it allows for horizontal mobility, seen as more conducive for the poor than the latter approach.

\section{Conclusion}

It seems that the "common" ideology amongst actors within ImpactUS is most apparent in their focus on human rights, much in line with the broader organizational cultural ideology. 
Yet, the policy issues of whether ImpactUS is neutral or political does not seem to be an agreed phenomenon among these actors even though it is public knowledge that the organization itself is meant to be an apolitical entity. Furthermore, it seems that there already is a deep-seated bias of partners such as NGOs being the cornerstone for sustainability. This brings to the realization that ImpactUS has formed its identity against ImpactEU along these lines. Todd's view on linkages to formal banking "as not necessarily a good thing" can be seen as a potentially heated debate waiting to happen in the decision-making process as this issue has been perceived as a given even in the self-help approach to social and economic mobility. Overall, the actors seemed to be well informed and introspective of their personal and professional experiences with definite viewpoints on the rights and wrongs of development.

Intercultural dialogue here has served as a strategic tool to unravel some unique viewpoints in decision-making on microfinance implementation. This is a much needed discourse in a field that has been substantively romanticized and where nuances in processes are for the most part uninvestigated. Hence, one can foresee these diverse perspectives playing an important role in shaping decision-making in community finance, sometimes more so than any mandate of the organization. Given that development organizations have more illusive benchmarks of success versus the profit-oriented benchmarks of the private sector, there is more room for individual and organizational culture to influence decision-making. This can spawn multiple projects from within the organization that may run parallel in theme but not necessarily in approach. Thereby, world culture meets organizational culture through intercultural dialogue in the shaping of microfinance strategies.

Overall, we should keep in mind that these actors are "development professionals" first and foremost. They survive on the business of development which demands that passion needs to 
move with donor funding; for example, NGOs that were fighting for gender empowerment yesterday may be channeling those same energies today for computer access for youth. To sustain ones integrity with these seemingly confronting ironies that decision-makers face, it seems that an underlying ideology or philosophy is constructed that is to some extent, independent of current development euphoria or organization endorsements; being true to character on the development stage is revealed.

\section{Acknowledgement:}

I would like to thank the referees for the excellent feedback received on this paper.

\section{References}

Anderson-Levitt, K. (2003). A world culture of schooling? In K. Anderson-Levitt (Ed.), Local meaning, global schooling, anthropology and world culture theory, pp. 1-26. New York: Palgrave Macmillan.

Author. (2005).

Author. (2006).

Bateman, M. (Nov 8, 2010). The distressing and entirely predictable situation in Andhra Pradesh: A personal comment by Milford Bateman. Retrieved on February 9, 2011 from the India Microfinance Business News website: http://indiamicrofinance.com/milfordbateman-andhra-microfinance-crisis-273203821.html

Bodea, G., \& Mustata, R.V. (2007). Intercultural communication, the basis of the organizational culture. Munich Personal RePEc Archive (MPRA) Paper No. 6215.

Boli, J., \& Lechner, F.J. (2005). World culture: Origins and consequences. Blackwell Publishing.

Cummings, T. G., \& Worley, C. G. (2005). Organization development and change. Thomson South-Western, USA,

Fernando, J.L. (2006). Microfinance: Perils and prospects. Routledge.

Jones, M.T. (2002). Globalization and organizational restructuring: A strategic perspective. 
Thunderbird International Business Review, 44(3), 325-351.

Morduch, J. (2000). The microfinance schism. World Development, 28 (4), 617-629.

Pritchett, L., \& Woolcock, M. (2004). Solutions when the solution is the problem: Arraying the disarray in development. World Development, 32(2), 191-212.

Rankin, K.N. (2004). Social capital, microfinance, and the politics of development. Feminist Economics, 8(1), 1-24.

Ringmar, E. (2005). Microfinance perils and prospects. London, Routledge.

Rosaldo, R. (1989). Culture and truth: The remaking of social analysis. Boston: Beacon Press.

Roy, A. (2010). Poverty capital: Microfinance and the making of development. New York: Routledge.

Schein, E. (2004). Organizational culture and leadership. San Francisco, Jossey-Bass.

Wooler, G.M., Dunford, C., \& Warner, W. (1999). Where to microfinance? International Journal of Economic Development, 1(1), 29-64.

\section{Chart 1}

Intercultural Perspectives amongst Key Decision-Makers within a Human-Rights Organization

Questions

Define

development

What is

Sustainability
Thomas

realizing world

community rights short and long-term: operational and partnering with local NGOs

\section{Fatima}

leveling the playing field; not just about access to economic resources

fallacy as there will always be a violation of human rights hope and change; eradicating poverty

Todd

build on already existing grassroots activities 


\begin{tabular}{|c|c|c|c|}
\hline $\begin{array}{l}\text { Role of external } \\
\text { actors }\end{array}$ & $\begin{array}{l}\text { limited due to the } \\
\text { "neutral" stance of } \\
\text { ImpactUS; challenging } \\
\text { yet essential for } \\
\text { organization to be } \\
\text { effective }\end{array}$ & $\begin{array}{l}\text { ImpactUS is deeply political as } \\
\text { human rights is inherently } \\
\text { political; essential to be } \\
\text { successful }\end{array}$ & $\begin{array}{l}\text { stimulator for exponential } \\
\text { and organic grassroots } \\
\text { replication of ideas like } \\
\text { SHGs }\end{array}$ \\
\hline $\begin{array}{l}\text { Indicators of } \\
\text { success \& Exit } \\
\text { Strategies }\end{array}$ & $\begin{array}{l}\text { women in leadership } \\
\text { positions; SHGs } \\
\text { spillover effect to other } \\
\text { sectors }\end{array}$ & $\begin{array}{l}\text { Exit strategy often unrelated to } \\
\text { success; determined by } \\
\text { funding and project agenda }\end{array}$ & $\begin{array}{l}\text { no direct answer; just } \\
\text { Africa is a proud culture }\end{array}$ \\
\hline Ethical challenge & $\begin{array}{l}\text { reasons for intervention } \\
\text { are often muddy }\end{array}$ & $\begin{array}{l}\text { to maintain equity in decision- } \\
\text { making }\end{array}$ & $\begin{array}{l}\text { questions whether people } \\
\text { should have the right to not } \\
\text { be interfered with and if } \\
\text { interventions are cultural } \\
\text { impositions }\end{array}$ \\
\hline
\end{tabular}

\footnotetext{
${ }^{1}$ The new heroes: Muhammad Yunus: a PBS interview: http://www.pbs.org/opb/thenewheroes/meet/yunus.html

${ }^{2}$ kool-aid is a metaphor used to describe how people uncritically embrace an ideology or understanding due to its popular appeal

${ }^{3}$ For reasons of confidentiality, I am using the pseudo name ImpactUS for this INGO.

${ }^{4}$ Although it appears below as simultaneous conversations, each decision-maker was interviewed separately; this has been done for thematic highlighting
} 